\title{
Lessons from the Fukushima Nuclear Power Accident
}

-Afterthoughts from Chairing the Investigation Committee-

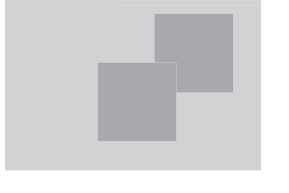

\author{
Professor, Kogakuin University, Professor Emeritus, \\ The University of Tokyo, Yotaro Hatamura
}

Investigation and verification of the Fukushima Nuclear Power Plant Accident led the author to lessons for design engineers and the society as well. The essence of the accident is not just about what happened inside the plant but it also involves a large number of local residents evacuated from their homes and still cannot return due to the release of radioactivity. This paper reports the following aspects that we shall learn from this accident; verify the passage to success and to failure as well, plan in the inverse direction about what we need by hypothesizing what could happen, and understand the danger associated with nuclear power if we want to continue using it. My expectations towards nuclear engineers are also explained.

\section{Introduction}

The author accepted the government assignment to the Chair of the Investigation Committee on the Accident at the Fukushima Nuclear Power Plants (NPP). The committee published an interim report in December 2011, and the final report in July 2012 to conclude its investigation. The investigation revealed that the nuclear power industry's attitudes as well as preparation towards accidents were insufficient.

For example, thorough planning and preparation to the fullest extent possible for tsunami as well as earthquakes were necessary, however, the industry never conducted such preparation and ended up face this accident.

This paper reports, whether we will abandon nuclear power generation in the future or continue to use it, what we shall learn from this accident and what we expect for people in nuclear power engineering. Furthermore, my expectations towards nuclear engineers after this accident are also mentioned.

DOI : 10.15669/fukushimainsights.Vol.3.23

(C) 2021 Atomic Energy Society of Japan. All rights reserved.

Originally published in Journal of the Atomic Energy Society of Japan (ISSN 1882-2606), Vol. 55, No. 1, p. 24-28 (2013) in

Japanese. (Japanese version accepted: November 7, 2012) 


\section{Understanding the Accident}

\section{Sequence of Events at the NPP}

The nuclear power plants faced events one after another and these events were just natural consequences that should have been foreseen.

On March 11, 2011, the Great East Japan Earthquake hit and Fukushima Daiichi NPP lost its external power source to the shaking. A series of tsunami followed the earthquake submerging the plant's switchboards and most of the emergency power sources. The nuclear reactors turned uncontrollable and accumulated decay heat within the reactor pressure vessels (RPV). Increase of the fuel rod temperature raised the temperature and pressure in the RPVs which then faced drops in the water levels.

The elevated fuel rod temperature caused reaction of the metal of fuel cladding tubes and water to release hydrogen gas that leaked into the reactor building and eventually triggered the hydrogen explosions (Figure 1). The RPV temperature, on the other hand, went up bringing the pressure up with it and caused RPV damage, then it released radioactivity into the containment vessel $(\mathrm{CV})$. High temperature and pressure further damaged the $\mathrm{CV}$ releasing radioactivity to the outside. Many may have the impression that the hydrogen explosions spread large amounts of radioactivity, however in reality, the explosions contributed to a fewer amount compared the release through damages to the vessels.

Rise in the RPV temperature led to the CV temperature increase and the water-level sensors gave incorrect readings.

Lowered water levels exposed the fuel rods and $\gamma$-rays passed through the RPV walls into the $\mathrm{CV}$. Elevated radioactivity in the $\mathrm{CV}$ hindered workers from opening the valves.

These unsurprising phenomena upon severe accidents should have been foreseen with planned counteractions, however, without such a priori measures, the operators could not see through the incorrect indicator of water-level sensors, and no remote mechanical operations were available.

\section{Invisible Cloud of Radioactivity Arrived}

Nuclear power disasters are not contained within the power plants. The influence of radioactive material when they are released and spread over a wide area extends for decades.

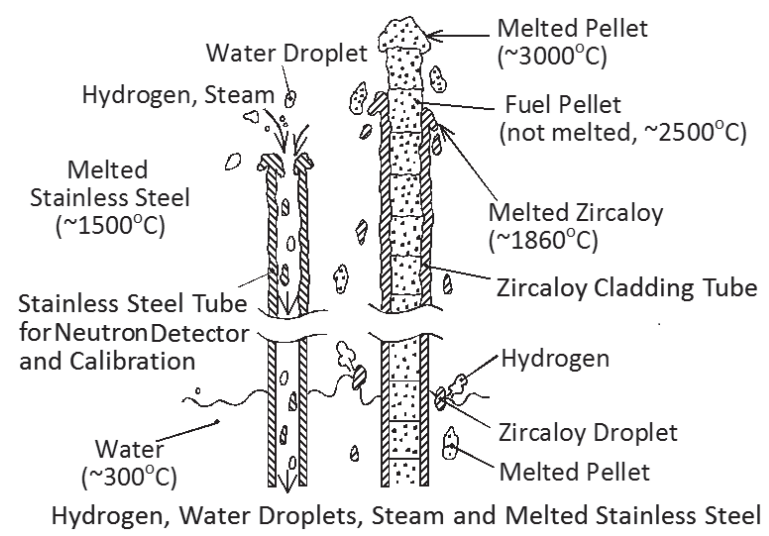

Figure 1 Illustration of phenomena inside RPV (Melted fuel rods led to hydrogen gas release and its escape to the outside of RPV) 


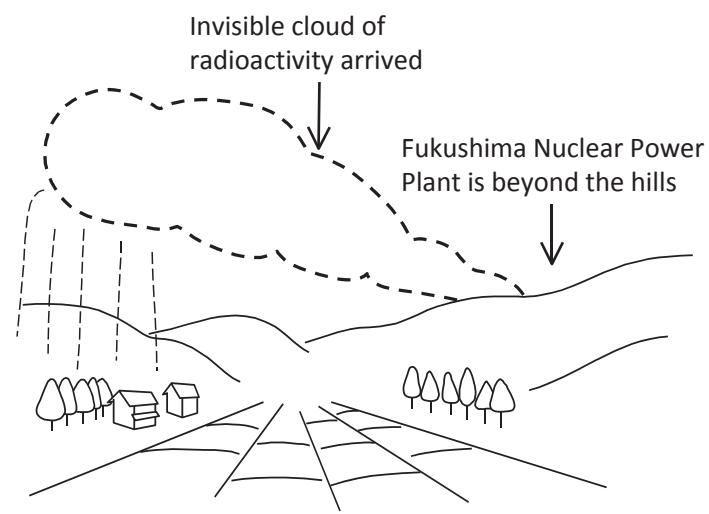

Figure 2 Cloud of radioactivity that reached Hiso area of Iitate-mura (Sketch by Hatamura based on hearings from local residents)

Figure 2 shows how the local residents perceived the arrival and fallout of the radioactive material. The author drew the sketch based on hearings from forced evacuees of Iitate-mura ${ }^{1}$ who visited $\mathrm{Hiso}^{2}$ district with the author. Invisible clouds of radioactivity arrived at the area and rain brought it down onto trees, buildings, land, and farmland. The fallout made the village uninhabitable.

We cannot fully understand nuclear power unless we look at what happens with radioactivity fallout from the viewpoint of the victims. Just the phenomena inside the power plants are not enough. For that purpose, we need to visit the location, see and feel the objects and talk with local residents (The author calls them the "three realities"). Secondhand information from those not directly involved or those quantitatively processed to an existing format will not let us accurately understand the situations.

\section{What to Learn}

Nuclear power is in fact attractive but at the same time involves great danger as energy, and the Fukushima NPP Accident taught us what we have to think about, prepare, and how to handle the technology. We need to thoroughly learn lessons from this accident.

\section{Only Knowledge can be Passed On -Afterthoughts As the Chairperson-}

The author listed 7 points in the last section of the report by the government investigation committee as thoughts by the Chair. My inauguration address stated, "The investigation shall withhold an evaluation by our next generation 100 years from now" because separate events, analyses, and summaries will be lost in the long run. The report ${ }^{1)}$ puts together generalized knowledge at a higher level so people in the coming decades can make use of the knowledge from this accident to social situations and technologies of their times.

\footnotetext{
${ }^{1}$ Iitate-mura: "Mura" is one of the administrative districts "shi", "cho" (machi), "son" (mura), "ku" of Japan. The wider district "prefecture" (ken) consists of a number of shi, cho, son, and ku. There are 47 prefectures, like Tokyo, Osaka, or Fukushima, in Japan. Iitate-mura is $230 \mathrm{~km}^{2}$ wide, with a population of 6,132 on March 1, 2011.

${ }^{2}$ Hiso: Hiso is the name of one of the sub-regions of Iitate-mura. A sub-region does not have administrative distinctions with others.
} 


\section{2. "Passage to Failure" and "Passage to Success"}

In the midst of an accident we need to make choices, decide, and carry out the decisions. When the overall outcome failed, we can trace the "passage to failure" by connecting the choice at each stage of the entire process. On the other hand, there is a path that would have led to success if we had made different choices at these stages. This is the "passage to success" (Figure 3).

Most accident investigations proceed by analyzing only the sequences to failure, however, to make use of what we learn from the accident, we shall build hypotheses to clarify the knowledge of what selection or decision at each stage would have led to success.

Upon an emergency situation like an accident, we can only apply what we had planned earlier. We need to plan ahead of time what phenomena will take place and how to counter them and organize the analyses on the shelves in our heads. When the time comes to make choices and decide, it is impossible to build the logic one by one to make the right action in response to the process of events at the time. Each choice is made based only on what is visible at the time. Those in charge, therefore, have to understand that they are making judgments without the overall picture, and should always be ready to capture the overall picture at all time.

\section{Learning from Other Industries}

We learned the hard way from this accident that nuclear power technology has not yet gained enough experiences of failure as well as success; the technology is young and vulnerable.

The author concluded a hypothesis that "A specific technology takes 200 years to build enough failure experience" by reviewing the history of boilers, one of the core technologies since the industrial revolution. Invented in the 18th century, the boiler was established as a practical technology in the early 19th century, however, as its pressure increased, so did the number of accident victims. As a countermeasure, we set a number of safety regulations and with the development of new material and welding techniques, its safety gradually reached higher levels and American Society of Mechanical Engineers (ASME) lowered the factor of safety to 4 from 5 in 1942. Severe accidents with boilers have not occurred since then. ASME further, in 1998, lowered the factor from 4 to 3.5. The boiler took about 200 years to build

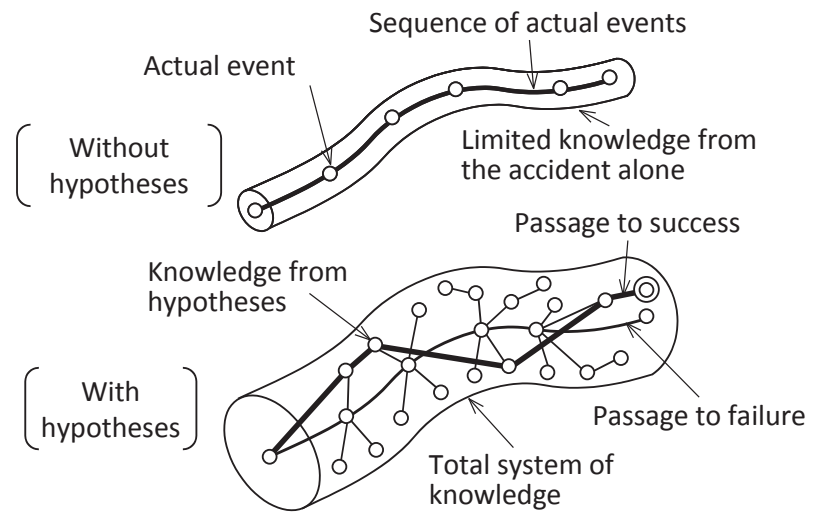

Figure 3 Adding hypotheses to the actual events of an accident leads to an enriched system of knowledge 
enough experiences to reach today's state of safety.

Figure 4 shows this history of boiler technologies together with those of trains, automobiles, and airplanes.

The nuclear power industry, on the other hand, started its commercial operation around 1950 and today (2012), has reached only about 60 years of operation. There have been three severe accidents during these 60 years; Three Miles Island (1979), Chernobyl (1986), and Fukushima (2011). The direct causes of these three accidents respectively were human error, wrong design concept of a divergent system, and lack of preparedness towards natural disasters of earthquake and tsunami. Following the above hypothesis, the nuclear power industry still has 140 years to gain more experience of failures. The author believes that we can significantly shorten this learning period by making use of knowledge gained in other industries. To realize this accelerated learning, the nuclear power industry needs the modesty and flexibility to learn knowledge from other industries without being isolated. The industry should not build its own "nuclear village ${ }^{3}$."

Here is an example of knowledge, common in other industries, but not shared by those in the nuclear industry; With large size plants in the chemical engineering industry, emergency equipment like piping for fire extinguishing are never buried underground so leakages can be spotted. The Kashiwazaki-Kariwa NPP, however, had installed the piping underground and when the Mid Niigata Prefecture Earthquake in 2004 hit, they could not put out the fire that broke out in the voltage transformer facility because the piping broke under the ground. This is an example of not learning from common knowledge in other fields to worsen the already bad situation.

To shorten the 200-year learning period, those in the nuclear power industry need to widen their fields of view to learn not only from this accident but also from knowledge gained through accidents that took places in other industries as well as those that happened overseas.

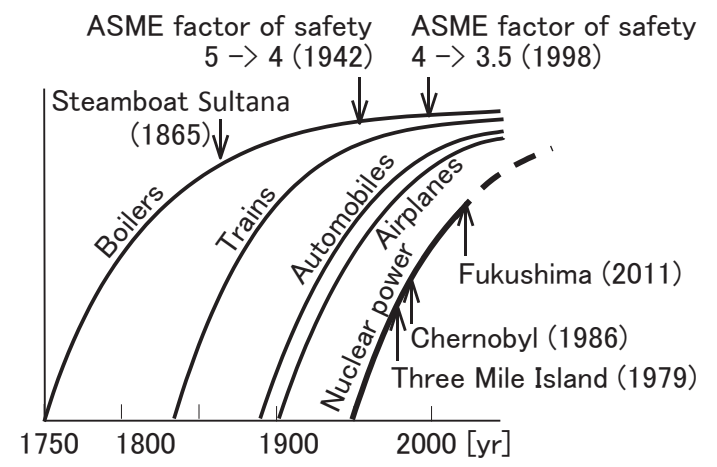

Figure 4 Any industry takes 200 years to gain enough experience of failures -Nuclear Power is only 60 years old-

\footnotetext{
${ }^{3}$ Nuclear village: a cynical term to describe the closed circle of utility companies, manufacturers, government organizations, and academia that all claimed that nuclear power is safe. Although there has never been such a formal organization, the mass media blamed it to mislead people and themselves to believe the safety and necessity of nuclear power.
} 


\section{What to Do Now}

\section{Countering the Radioactivity Contamination}

The most serious fact with this accident is that radioactive material spread over a wide range affecting residents and the environment. The size of the affected area and the strength of radioactivity is not just a short-term issue. The influence will last for a longer period and we have to continue the counteraction for a long time.

We have to first acknowledge that we cannot extinguish radioactivity. The word "decontamination" may give the wrong impression that we can eliminate radioactivity with some sort of reaction like with the case of other chemical material. The reality is that we have to store the contaminated materials at some place where the effects is less, and only thing we can do is to wait until its radioactivity decays off.

The primary concern now is cesium-137. It has a half-life of 30 years and its influence will be negligible within 100 years. We need to store the contaminated materials until then. We cannot set a single or just a few large areas for storage, because of difficulty of securing such grounds. It will be most practical to dig storage holes in the fields and backyards to keep the contaminated materials in a number of small quantities (Figure 5). We shall build a long term plan so the area is fully resurrected 100 years from now.

\section{Everything Changes and People's Minds as well}

Today, the mood for abandoning nuclear power generation is highly elevated in Japan. If we do abolish nuclear power generation, however, we cannot produce enough electrical power with just renewable energy and thus we have to import alternate fuel. The importing will not only lead us to higher electricity bills but it will also expose our vulnerability of relying on foreign countries for energy sources.

Making the judgment to abandon nuclear power now, on the other hand, may lead us to reaffirm the need of nuclear power within several decades. In the United States, for example, a new nuclear reactor was not built for 30 years after the Three Mile Island Accident, however, the higher need for nuclear power in recent years led to a decision to build new ones. This fact, when reflected upon a country like Japan with hardly any natural resources, may guide us to face the need for nuclear power again in the future.

The reason for selecting such a dangerous energy source of nuclear power was because the

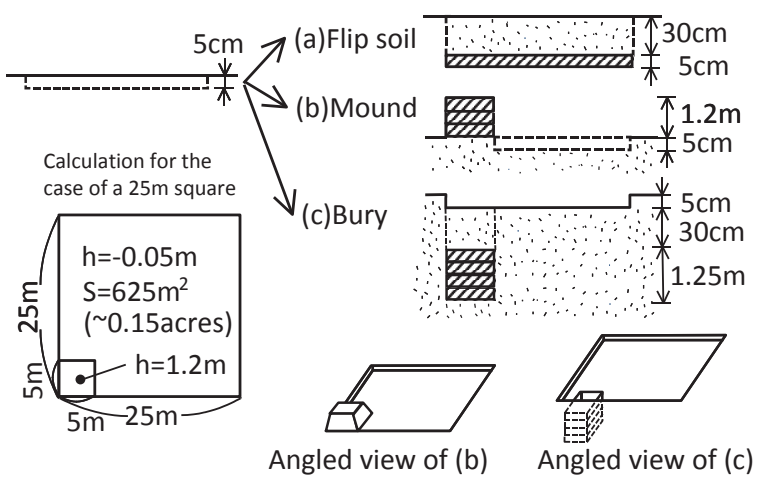

Figure 5 Practical handling of contaminated soil is mounding or burying 
society as a whole was badly in need for electric power. As the economy turned active after the World-War II, the country faced an unprecedented demand for electricity, and the limited supply then was a constraint in expanding the economy and elevating the quality of people's lives. The decision to adopt nuclear power generation was made then to break the situation.

Before the nuclear industry started, the Kurobe dam construction started in 1956 and cost 51.3 billion JPY (twice the capitol of Kansai Electric Power Company then). The total power generation from Kurobe river power plant 4 was $340 \mathrm{MW}$ that is even less than the Fukushima Daiichi Unit-1 power of 460 MW. The newest nuclear power plant in Japan has the capacity to generate about 1,300 MW a unit. This is about 4 times the capacity of Kurobe. It probably is not an exaggeration to say that our lives to freely use electricity without even thinking about the sources owes it to nuclear power generation. Whatever we conclude about the future of nuclear power, we shall not forget our history of the strong need for electricity we experienced in the past.

\section{About Resuming Operations}

We need to plan, not only about preventing disasters, but also about reducing their seriousness assuming accidents do happen. The myth that "nuclear power is safe" and the fact that many of us blindly believed it was in fact an abnormal state of the society. The Fukushima Daiichi NPP Accident taught us that for reducing the seriousness of accidents, the forward thinking of thorough planning and preparation to operate NPPs effectively and safely is insufficient. We must bear in our minds that we shall assume that accidents happen and we need the inverse thinking of what events will lead to severe accidents, what phenomena follows on, and how we can minimize the damage once they take place.

Up until the Fukushima Daiichi NPP Accident, the nuclear power industry was concerned with elevating the safety of nuclear power generation, of how to effectively and safely generate power and prevent accidents with regulations and rules. The accident, however, broke out anyway.

Nuclear power naturally has high energy density and thus is extremely dangerous. To deal with such a dangerous technology, "accident prevention" that is only concerned with how to prevent accidents is insufficient, and it is clear that we need to assume that accidents do happen and we shall plan ahead of time to the maximum extent possible about how to reduce the seriousness of disasters once they take place. We need to make the maximum efforts to prevent accidents, and at the same time, prepare "disaster reduction" plans to prevent the spread of damages and actually carry out emergency drills.

We have to say that evacuation triggered by the accident did not go smoothly. Futaba hospital, for example, evacuated patients that were not to be moved and the action turned into a tragedy of letting many of the patients die because of the evacuation. To prepare for evacuation, we must not only prepare plans and locations, but it is extremely important to organize evacuation drills with the participation of all residents. The 160,000 forced evacuees are still reporting anxiety about their unclear future. We need to be well prepared with long term plans to look after the evacuees from the time of evacuation until they recover their original lives back.

The stopped NPPs will be evaluated for restart once the stress tests to confirm safety prove acceptable. Restarting the NPPs with such a process is, however, questionable. There will always be oversights or areas that we fail to recognize (Figure 6). Without changing the basic thinking ways and just analyzing different phenomena or tightening the checking do not lead us to find missed points. The accident we faced this time was caused by tsunami that we 


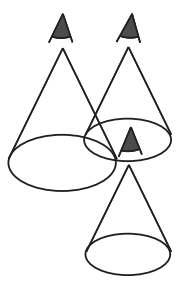

(a) Visible range

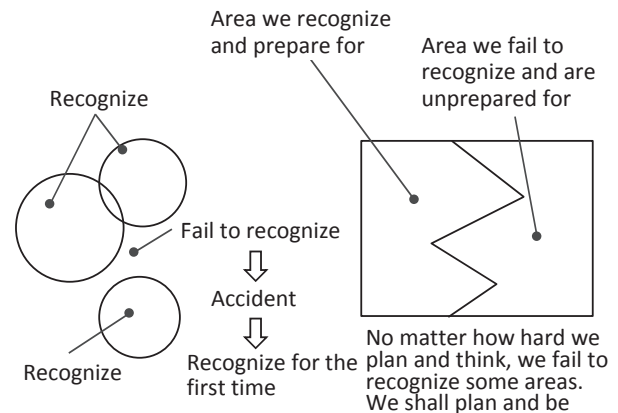

(b) Where we do and do not recognize
Wre shall plan and be

encounter with such areas.

(c) Correct planning

Figure 6 Despite our hard thinking, there remains areas that we fail to recognize

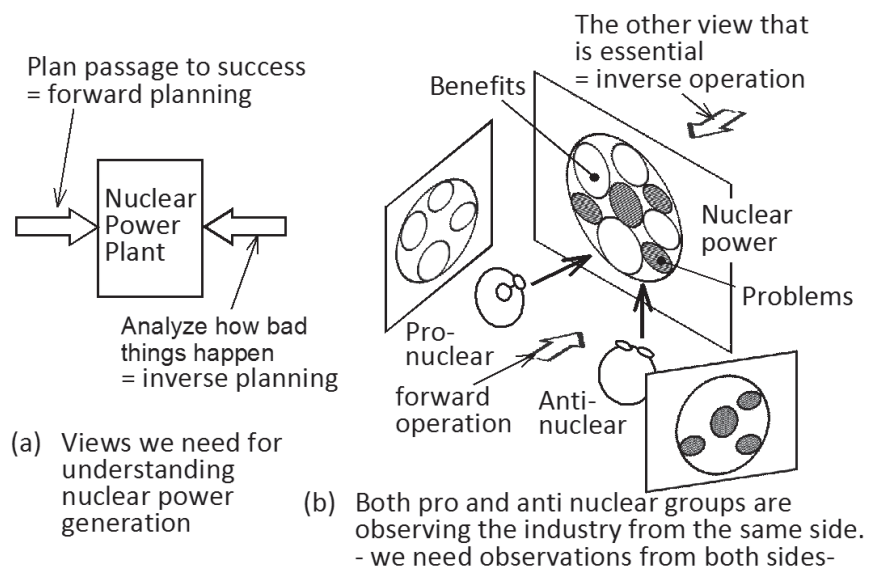

Figure 7 Visions needed for the coming nuclear power industry

failed to think about them. We should realize that starting from the assumption that we have no oversight would always lead to the cause of trouble in the future.

The discussion so far leads us to realize that what we need is to "in addition to how things can go well (forward planning), think how bad things happen (inverse planning)," by recognizing "what could happen do happen," in other words, assume that accidents do happen and analyze them in the inverse direction. This is probably the biggest lesson we learned from this accident (Figure 7).

To evaluate whether to restart the NPPs or not, we shall admit the dangers and conduct thorough discussions comparing such disadvantages with the convenience they produce.

\section{Expectations towards People in Nuclear Engineering}

After the Great East Japan Earthquake and subsequent tsunami waves crippled the cooling systems of the Tokyo Electric Power Company (TEPCO) owned Fukushima NPP on March 11,2011 , many specialists including employees from the utility company, regulating organizations, and academia frequently used the word "unexpected." Viewers developed the 
impression that they were trying to "escape responsibility saying it couldn't have been helped because they were unexpected." The people thought it was their responsibility to have prepared to prevent serious outcomes even with the great disaster this time because they have been operating under the safety myth that "nuclear power is safe."

\section{Explain so People Can Understand -Information Announcements and Technical Explanation-}

Upon this accident, a large number of information and technical commentaries were sent out to the society, however, we heard many complaints about the news and explanations. Information and explanations shall be given with the understanding of what the receivers are looking for, otherwise the intended contents will not reach them accurately. People tend to think they are "hiding" if the information does not reach the audience at the right time, and "lying" if the contents do not match the expectations. To avoid such misunderstanding, detailed information release in ways easy for the audience to understand is needed.

Also, information and technical explanations for this accident often included technical jargon and acronyms that were hard to follow without special knowledge of the field. The phrase, for example, "operated the valve manually" led many of us to imagine workers going out to the field to turn a handle attached to the valve. The fact in this case, was that the operator in the central control room manually turned a switch on the operation panel to send a signal to the control board that runs on DC power, and its output operated a solenoid valve to send compressed air to an air cylinder connected to a rack and pinion, beveled gear, or a linkage to rotate the butterfly valve. Many people, however, lack the knowledge of so many elements in this operation and from the phase "Manually operating the valve did not work" alone cannot image the precise picture of what happened. The person sending information shall accurately relay the meanings of technical terms and acronyms and at the same time arrange the information in ways easier for the audience to understand.

Today, all the Japanese need to have correct understanding of nuclear power and radioactivity, thus we expect proper information broadcasting from nuclear engineers.

\section{Keeping the Technology Alive}

This nuclear power accident was one of the worst failures in the history of human. We, however, should not handle it as if it is a taboo that we should not laid our hands on. Whether we stop using nuclear power or we restart it, we shall keep the related knowledge up to date to hold the nuclear power technology alive.

One reason is because we have to carry out the decommission processes of the Fukushima NPPs. Another is the fact that we will be left with the spent nuclear fuel even if we decide to abandon nuclear power. Furthermore, emerging and developing countries are eager to adopt nuclear power generation and even if Japan stops using nuclear power, it is questionable whether we should not carry with us the technology or not. To own the technology for exportation or not is another question. And as the former section explained, even if we decide not to restart the NPPs, it may be needed within several decades down the road.

To see progress in nuclear engineering, I expect those involved to not just reflect on the mistakes made but also to thoroughly study whatever they can from this accident and to keep developing it as one of the proper technologies. Unless those involved in the nuclear industry work with confidence and pride, it will be extremely unfortunate at least for the Japanese society. 


\section{INSIGHTS CONCERNING THE FUKUSHIMA DAIICHI NUCLEAR ACCIDENT Vol. 3}

I discussed afterthoughts of serving as the chair of the Investigation Committee on the Accident at Fukushima Nuclear Power Plants. I hope the people in the nuclear power industry understand my discussions and will make use of them.

\section{Reference}

1) Final Report, Investigation Committee on the Accident at Fukushima Nuclear Power Stations of Tokyo Electric Power Company, Medialand Works Pub., 2012. 